\title{
Role of transvaginal sonography in various gynecological disorders
}

\author{
Pooja J. Mise ${ }^{1 *}$, Sangamesh J. Mise ${ }^{2}$, Aditya Mise ${ }^{2}$, Margol Siddappa ${ }^{3}$,
}

${ }^{1}$ Department of Obstetrics and Gynecology, GIMS, Kalaburagi, Karnataka, India

${ }^{2}$ Department of General Surgery, MRMC, Kalaburagi, Karnataka, India

${ }^{3}$ Department of Medicine, Gulbarga Heart Foundation, Kalaburagi, Karnataka, India

Received: 07 June 2017

Accepted: 19 June 2017

\author{
*Correspondence: \\ Dr. Pooja J. Mise, \\ E-mail: poojasiddum@gmail.com
}

Copyright: (C) the author(s), publisher and licensee Medip Academy. This is an open-access article distributed under the terms of the Creative Commons Attribution Non-Commercial License, which permits unrestricted non-commercial use, distribution, and reproduction in any medium, provided the original work is properly cited.

\begin{abstract}
Background: Transvaginal sonography (TVS) is a new diagnostic technique used for the evaluation of the female pelvis. The objective of the present study was to study the role of TVS and to assess the diagnostic accuracy in gynecological disorders.

Methods: Total number of 100 patients attending OPDs with various complaints was selected by random technique of the study. All the patients have informed consent and thorough clinical examination including general, systemic and pelvic examination was conducted after taking a detailed history then the patients underwent TVS followed by one of the procedures like fractional curettage, dilatation and curettage and abdominal hysterectomy (with or without conservation of ovaries) or conservative management with regular follow up.

Results: The sensitivity of TVS in diagnosing dysfunctional uterine bleeding (DUB) and pelvic inflammatory diseases (PID) was $100 \%$ and specificity was $85.1 \%$ and $95 \%$ respectively. For fibroids and ovarian mass diagnosis, sensitivity was $68.9 \%$ and $80.9 \%$ respectively and specificity was $100 \%$. Diagnostic accuracy of clinical diagnosis was $70.0 \%$ whereas TVS had $94.0 \%$ of diagnostic accuracy in diagnosing various gynecological disorders.

Conclusions: The final outcome is that TVS examination is an important non-invasive investigation, can be used as important diagnostic method in various gynecological disorders as it has got a high diagnostic accuracy.
\end{abstract}

Keywords: Carcinoma endometrium, DUB, Endometrial polyp, Histopathological examination, Ovarian cyst, PID, Transvaginal sonography

\section{INTRODUCTION}

Ultrasound is the initial diagnostic technique used for imaging pelvic pathologies that was greatly appreciated. ${ }^{1}$ With introduction of grayscale images, real time scanning and construction of small transducer resulted in breakthrough of endovaginal sonography, transvaginal and transrectal sonography and can be regarded as further extension of pervaginal and rectal examination. Now obstetrician and gynecologists have started realizing that convincing diagnosis and best patient care are possible only by the use of routine ultrasonography in their clinical practice. ${ }^{2}$

Since the introduction of transvaginal sonography practicing obstetrician and gynaecologist are further encouraged to take sonographic diagnosis. Transvaginal sonography (TVS) which can be seen through pelvis, visualize the deeper structures and even note the fine details of the organs like fallopian tube and ovary. ${ }^{3}$ High 
frequency of TVS is useful in diagnosis of adnexal masses, dysfunctional uterine bleeding (DUB), pelvic inflammatory diseases (PID) and pain, uterine enlargement, ectopic pregnancy, etc. In addition, TVS has become an invaluable tool for the care of infertility patients. ${ }^{4}$ It is used for follicular study and also used to diagnose congenital anomalies, leiomyoma, and to evaluate endometrium.

The present study was conducted with the aim to study and diagnose the accuracy of TVS in various gynecological disorders.

\section{METHODS}

The present study was undertaken at M. R. Medical College, Gulbarga i.e., Basaveshwar Teaching and General Hospital and Sangameshwar Teaching and General Hospital, Gulbarga from November 2010 to October 2012.

A total of 100 patients attending the OPDs with complaint of menstrual irregularities, pain abdomen, mass per abdomen, infertility was selected for the study. Informed consent was taken from all the patients and local ethical approval was obtained. A thorough clinical examination including general, systemic and pelvic examination was conducted after taking a detailed history. Complete blood and urine investigations were done.

Inclusion criteria were patients with menstrual irregularities, uterine and adnexal masses, pelvic inflammatory diseases, chronic vaginal discharge, ovarian masses and infertility problems. Exclusion criteria were pregnant women and patients with large pelvic masses.

All the patients underwent TVS by using HITACHI EUB-7000 HV ultrasound system with 5-9 $\mathrm{MHz}$ transvaginal probe (Figure 1 and 2) followed by one of the invasive procedures like fractional curettage, dilatation and curettage, abdominal hysterectomy (with or without conservation of ovaries) or conservative management with regular follow-up.

The accuracy of transvaginal sonography in depicting the type of endometrium, in diagnosing DUB, fibroid, ovarian cyst, endometrial polyps, carcinoma endometrium, pelvic inflammatory diseases was calculated by comparing its findings with clinical diagnosis with sensitivity, specificity, positive predictive value (PPV) and negative predictive value (NPV).

\section{RESULTS}

Table 1 presents the demographic characteristics of the study participants. Among the 100 cases, majority of the patients were in the age group of 30-40 years i.e., $46 \%$ cases and $12 \%$ cases in $20-30$ years, $32 \%$ cases were between $41-50$ years and $10 \%$ between $50-60$ years. $95 \%$ women were multiparous and $5 \%$ were nulliparous.

\section{Table 1: Socio-demographic characters of the study participants.}

\begin{tabular}{|l|l|}
\hline Characteristics & No. of patients \\
\hline Age (in years) & \\
\hline $20-30$ & 12 \\
\hline $31-40$ & 46 \\
\hline $41-50$ & 32 \\
\hline $51-60$ & 10 \\
\hline Parity & \\
\hline Nullipara & 05 \\
\hline Multipara & 95 \\
\hline
\end{tabular}

In this study, majority of patients presented with menstrual irregularities $52 \%$ cases, the commonest bleeding pattern was menorrhagia in $36 \%$ cases and polymenorrhea in $16 \%$ cases. $41 \%$ cases presented with pain abdomen, $2 \%$ with infertility, $3 \%$ with mass per abdomen and $2 \%$ cases presented with post-menopausal bleeding as shown in Table 2.

\section{Table 2: Distribution of various symptoms.}

\begin{tabular}{|ll|}
\hline Symptoms & Number of cases \\
\hline Menstrual irregularities & 52 \\
\hline a. Menorrhagia & 36 \\
\hline b. Polymenorrhea & 16 \\
\hline Pain abdomen & 41 \\
\hline Infertility & 2 \\
\hline Mass per abdomen & 3 \\
\hline Postmenopausal bleeding & 2 \\
\hline Total & 100 \\
\hline
\end{tabular}

Table 3: Distribution of cases based on diagnosis.

\begin{tabular}{|lll|}
\hline Diagnosis & $\begin{array}{l}\text { No. of cases of } \\
\text { clinical findings }\end{array}$ & $\begin{array}{l}\text { No. of cases of } \\
\text { TVS findings }\end{array}$ \\
\hline DUB & 37 & 26 \\
\hline Fibroid & 20 & 29 \\
\hline PID & 24 & 20 \\
\hline Ovarian cyst & 17 & 21 \\
\hline $\begin{array}{l}\text { Carcinoma } \\
\text { endometrium }\end{array}$ & 2 & 2 \\
\hline $\begin{array}{l}\text { Endometrial } \\
\text { polyp }\end{array}$ & 0 & 2 \\
\hline Total & 100 & 100 \\
\hline
\end{tabular}

Table 3 presents the diagnosis of symptoms determined clinically and by transvaginal sonography. After taking history and clinical examination, 37 cases were diagnosed as DUB, 20 cases were diagnosed as fibroid uterus, 24 cases were diagnosed as PID, 17 patients as ovarian mass. 2 patients were suspected to have carcinoma endometrium. These, 100 women were subjected to transvaginal sonographic examination, out of which 26 women were diagnosed to have DUB, fibroid uterus was 
diagnosed in 29 cases, 20 cases were diagnosed as PID, 21 cases as ovarian mass, 2 cases as carcinoma endometrium and 2 cases were diagnosed as endometrial polyp.

\section{Table 4: Distribution of fibroid uterus based on} TVS findings.

\begin{tabular}{|ll|}
\hline Type of fibroid & Number of cases \\
\hline Intramural & 11 \\
\hline Submucosal & 10 \\
\hline Multiple intramural fibroid & 5 \\
\hline Subserosal & 3 \\
\hline Total & 29 \\
\hline
\end{tabular}

Clinically 20 patients were diagnosed of having fibroid uterus, and were confirmed by TVS. Other 9 more cases which were diagnosed as DUB clinically, they were diagnosed as fibroid uterus by TVS. Among total 29 cases of fibroid uterus, 11 cases were intramural fibroid 10 cases were submucosal fibroid, 3 cases were subserosal fibroid, 5 cases were multiple intramural fibroid as shown in Table 4.

Table 5: Distribution of cases based on endometrial thickness and histopathological examination.

\begin{tabular}{|c|c|c|}
\hline & No. of cases $(n=26)$ & $\%$ \\
\hline \multicolumn{3}{|c|}{ Endometrial thickness } \\
\hline $5-10 \mathrm{~mm}$ & 5 & 19.23 \\
\hline $10-15 \mathrm{~mm}$ & 12 & 46.15 \\
\hline$>15 \mathrm{~mm}$ & 9 & 34.61 \\
\hline \multicolumn{3}{|c|}{ Histopathological examination } \\
\hline Proliferative & 10 & 38.46 \\
\hline Secretory & 4 & 15.38 \\
\hline $\begin{array}{l}\text { Endometrial } \\
\text { hyperplasia }\end{array}$ & 9 & 34.61 \\
\hline Adenomyosis & 3 & 11.53 \\
\hline
\end{tabular}

Clinically 30 patients were diagnosed of having DIB, of them 26 were diagnosed of having fibroids by TVS. In these cases, endometrial thickness was measured and sent for histopathological examination to describe their anatomical natures.

The endometrial thickness ranging from 5-10 $\mathrm{mm}$ in 5 cases, $10-15 \mathrm{~mm}$ in 12 cases and more than $15 \mathrm{~mm}$ in about 9 cases. Proliferative pattern of endometrium was seen in 10 cases. Secretory pattern in 4 cases, 9 cases had endometrial hyperplasia. 3 cases had adenomyosis on HPE, which were not diagnosed by transvaginal sonography and were misdiagnosed as DUB (Table 5).

In the present study, 17 cases were diagnosed as ovarian cyst clinically i.e., by pervaginal examination and by TVS 21 cases were diagnosed of having ovarian cyst/ mass. Of them $59 \%$ of cases presented with ovarian mass in the age group of $20-40$ years $41 \%$ in the age group of 41-60 years as shown in Table 6. Out of 21 cases of ovarian cysts, 9 were simple ovarian cyst. 6 were serous cystadenoma, 4 were complex ovarian cysts, and 2 cases as mucinous cystadenoma.

Table 6: Age and type wise distribution of ovarian cysts among cases.

\begin{tabular}{|c|c|c|}
\hline & $\begin{array}{l}\text { No. of cases } \\
(n=21)\end{array}$ & $\%$ \\
\hline \multicolumn{3}{|l|}{ Age group (years) } \\
\hline $21-30$ years & 4 & 19.04 \\
\hline $31-40$ years & 9 & 42.8 \\
\hline $41-50$ & 5 & 23.8 \\
\hline$>50$ & 3 & 14.28 \\
\hline \multicolumn{3}{|l|}{ Type } \\
\hline Simple ovarian cyst & 9 & 42.8 \\
\hline Serous cystadenoma & 6 & 28.57 \\
\hline Complex ovarian cysts & 4 & 19.04 \\
\hline Mucinous cystadenoma & 2 & 9.5 \\
\hline
\end{tabular}

By clinical examination, out of 17 cases, 10 cases were diagnosed as right sided ovarian cyst and 7 cases as left sided ovarian cyst. But by transvaginal sonography, out of 21 cases, 13 cases were right sided ovarian cyst and 8 cases as left ovarian cyst (Table 7).

Table 7: Side wise distribution of ovarian cysts.

\begin{tabular}{|lll|} 
Side & $\begin{array}{l}\text { By clinical } \\
\text { examination }\end{array}$ & $\begin{array}{l}\text { By transvaginal } \\
\text { sonography }\end{array}$ \\
\hline Right sided & 10 & 13 \\
\hline Left sided & 7 & 8 \\
\hline Total & 17 & 21 \\
\hline
\end{tabular}

Among 24 women diagnosed as PID, based on history and clinical examination, only 20 cases were diagnosed as PID, 4 cases were diagnosed as ovarian cyst.

Majority of patients presenting with PID, range in the age group of $36-50$ years i.e., 15 cases $(50 \%)$ as shown in Table 8 .

Table 8: Age wise distribution of PID cases.

\begin{tabular}{|l|l|l|}
\hline Age group (years) & No. of cases & $\%$ \\
\hline $20-35$ years & 8 & 40 \\
\hline $36-50$ years & 10 & 50 \\
\hline$>50$ & 2 & 10 \\
\hline
\end{tabular}

Table 9 shows the comparison between transvaginal findings in considering diagnosis of various gynecological disorders with that of clinical diagnosis.

Transvaginal sonography had an excellent sensitivity of $100 \%$ in predicting DUB and PID and specificity of $100 \%$ in predicting fibroid and ovarian cysts. Transvaginal sonography being highly specific it can be used for diagnosing all gynecological disorders. 
Table 9: Comparison of clinical and transvaginal sonography with its sensitivity, specificity, PPV and NPV.

\begin{tabular}{|c|c|c|c|c|c|c|c|c|c|c|}
\hline \multirow{3}{*}{ Diseases } & \multirow{2}{*}{\multicolumn{2}{|c|}{ No. of cases }} & \multicolumn{4}{|c|}{ TVS } & \multirow{3}{*}{ Sensitivity (\%) } & \multirow{3}{*}{ Specificity (\%) } & \multirow{3}{*}{$\begin{array}{l}\text { PPV } \\
(\%)\end{array}$} & \multirow{3}{*}{ NPV $(\%)$} \\
\hline & & & \multicolumn{2}{|c|}{ True } & \multicolumn{2}{|c|}{ False } & & & & \\
\hline & TVS & Clinical & $+v e$ & $-\mathbf{v e}$ & $+v e$ & $-v e$ & & & & \\
\hline DUB & 26 & 37 & 26 & 11 & 0 & 63 & 100 & 85.13 & 70.27 & 100 \\
\hline Fibroid & 29 & 20 & 20 & 0 & 9 & 71 & 68.96 & 100 & 100 & 88 \\
\hline PID & 20 & 24 & 20 & 4 & 0 & 76 & 100 & 95 & 83 & 100 \\
\hline $\begin{array}{l}\text { Ovarian } \\
\text { cyst }\end{array}$ & 21 & 17 & 17 & 0 & 0 & 79 & 80.95 & 100 & 100 & 95.18 \\
\hline
\end{tabular}

\section{DISCUSSION}

Transvaginal sonography is one of the important diagnostic techniques used for evaluation of female pelvis. ${ }^{5}$ To date its most frequent use has been in the evaluation of ovulation, in oocyte recovery in infertile patients. TVS images yield more information about the origin of the mass and its internal architecture. ${ }^{6}$ Sladkevicius et al concluded that TVS measurement of endometrium was better discrimination between normal and pathological and between malignant endometrium than any Doppler variable. ${ }^{7}$ Anjali et al, in her study concluded that TVS could detect endometrial changes and can be well correlated with histopathology in $92 \%$ cases. ${ }^{8}$ Transvaginal sonography is a diagnostic tool for cases presenting with the problems of DUB and can play a major role in its diagnosis and management, as it has a greater patient compliance being a non-invasive OPD procedure.

In the present analysis, majority of the patients were under the age group of 31-50 years and recorded painless bleeding in 52 cases. Of 52, menorrhagia is the major symptom observed in 36 cases and polymenorrhagia in $16 \%$ cases. Similar clinical presentations' was seen in the previous studies of Veena et al in which menorrhagia was seen in $42 \%$ of cases and $14 \%$ presented with polymenorrhea. ${ }^{9}$ In the present study, $94.23 \%$ were multiparous and only $5.76 \%$ were nulliparous. In the study done by Al-Naaimy et al $94.2 \%$ were multiparous and $5.8 \%$ were nulliparous. ${ }^{10}$ Similar findings were observed in a study conducted by Bhosle et al in 2010 in which $96.42 \%$ patients were multiparous and $3.57 \%$ were nulliparous. ${ }^{11}$

In our study, proliferative and hyperplastic endometrium were found in $38.46 \%$ and $34.6 \%$ cases respectively indicating anovulation and unopposed action of estrogen is responsible for the most common type of DUB. $15.3 \%$ of the patients had secretory endometrium, thus indicating the ovulatory type of bleeding in DUB patients. On contrary, studies of Anjali et al showed that most of the cases of DUB were due to incidence of proliferative endometrium followed by endometrial hyperplasia and secretory endometriumin 48\%, 28\%, $12 \%$ cases respectively. ${ }^{8}$ The sensitivity and specificity of TVS in predicting the type of endometrium was $50 \%$ and
$100 \%$ respectively. The sensitivity of TVS in predicting the proliferative endometrium in the present study was comparatively less. The other figures are consistent with the study by Veena et al. ${ }^{9}$ The findings of our study show that ovarian masses are more prevalent in reproductive age group 20-40 years in 13 cases out of 21. Present findings are similar to studies by Sadia Khan et al, in which ovarian masses was seen in 19 cases out of $22 .{ }^{12}$ In the present study, TVS showed $100 \%$ accuracy rate in determining the side of ovarian masses and this was similar to the study conducted by Sadia Khan et al. ${ }^{12}$

Transvaginal sonography had an excellent sensitivity of $100 \%$ in predicting DUB and PID and specificity of $100 \%$ in predicting fibroid and ovarian cysts. In the present study, clinically 20 cases were diagnosed as fibroids, 37 as DUB. On TVS, 29 cases were diagnosed of having fibroids and 26 cases were having DUB. 9 cases of fibroid uterus were missed clinically and 11 cases of DUB were misdiagnosed by clinical examination. The present study correlated with the study by Bhosle et al, who diagnosed clinically $55(49.1 \%)$ as fibroid uterus, $49(43.8 \%)$ as DUB and $8(7.6 \%)$ as adenomyosis while on TVS, $53(47.3 \%)$ diagnosed as fibroid, $40(35.7 \%)$ as DUB, and $19(16.8 \%)$ cases were diagnosed as adenomyosis. ${ }^{11}$

The sensitivity of TVS in predicting DUB is $100 \%$, but specificity is $85.13 \%$, which is well correlated with the study conducted by Bhosle et al. ${ }^{11}$ The sensitivity of transvaginal sonography in predicting fibroid uterus was $68.96 \%$ that was similar with the findings of Subhankar et al 82 i.e. $65.9 \% .^{13}$

Pelvic inflammatory disease has a wide variation in the symptoms, some of which fail to imply a pelvic etiology. They may range from subtle or mild to severe. This requires the clinician to maintain a high index of suspicion for the diagnosis of pelvic inflammatory disease. Alternatively, the signs of PID are limited to inflammatory exudates from the lower genital tract and pelvic organ tenderness. The role of TVS in PID diagnosis is under much discussion. According to a study by Cicatore et al in 1992, its sensitivity depends on the image described, estimated between 32 and 85\%, with $58-100 \%$ specificity and is operator dependent. ${ }^{14}$ In the present study, 24 cases were clinically diagnosed as 
pelvic inflammatory disease. Out of which, 20 cases were diagnosed to have PID by TVS. The sensitivity, specificity, PPV and NPV of TVS in determining PID was found to be $100 \%, 95 \%, 83 \%$ and $100 \%$ respectively. On comparison with the studies of Gaiten et al the sensitivity $(87 \%)$ and specificity $(50 \%)$ of TVS was higher. ${ }^{15}$ In the present study, accuracy of transvaginal sonography in diagnosis of ovarian cyst was $90.47 \%$, which was similar to the other studies of Tongsong et al, in which the accuracy of TVS in diagnosis of ovarian mass was about $89.7 \% .^{16}$ The accuracy of clinical diagnosis and TVS in the present study was $70 \%$ and $94 \%$ respectively. This was in accordance with the findings of Batra et al in which clinical diagnostic accuracy was $69.1 \%$ and TVS diagnostic accuracy was $85.45 \% .{ }^{17}$ These results suggest that transvaginal sonography has high diagnostic accuracy in evaluation of various gynecological disorders.

\section{CONCLUSION}

Transvaginal sonography gives clear picture of individual pelvic organs and hence morphology can be studied in minute details. This is both due to closed proximity of transvaginal sonography probe to the pelvic organs imaged, and improved resolution of high frequency and low acoustic pulse transducer. The diagnostic accuracy of transvaginal sonography was very high in evaluating the entire gynaecological disorders. It helps in accurate diagnosis and therapeutic management of DUB, PID, ovarian cysts and infertility.

\section{Funding: No funding sources}

Conflict of interest: None declared

Ethical approval: The study was approved by the Institutional Ethics Committee

\section{REFERENCES}

1. Qureshi IA, Ullah H, Akram MH, Ashfaq S. Transvaginal Versus Trans-abdominal sonography in the evaluation of pelvic Pathology. J Coll Physicians Surg Pak 2004;14:390-3.

2. Nyberg DA, Hill LM. Transvaginal Ultrasound. $2^{\text {nd }}$ Edition. 1992

3. Modica MM, Timor-Tritsch IE. Transvaginal sonography provides sharper view into pelvis. J Obstet Gynecol Neonatal Nurs. 1998;17(2):89-95.

4. Markov D, Ginekol A. Transvaginal ultrasonography - Clinical implementation in benign gynecological disorders. 2010;49(1):42-58.

5. Schoenfeld A, Levavi H, Hirsch M, Pardo J, Ovadia J. Transvaginal sonography in postmenopausal women. J Clin Ultrasound. 1990;18(4):350-8.

6. Niazi M, Kamal MM, Malik N, Farooq MA, Wahid N. Transabdominal Vs Transvaginal Sonography -
Comparison in Pelvic Pathologies. JRMC. 2015;19(3):223-6.

7. Sladkevicius P, Valenten L, Marsal K. Endometrial thickness and Doppler velocimetry of the uterine arteries as discriminator of endometrial status in women with postmenopausal bleeding. A comprehensive study. Am J Obstet Gynecol. 1994;171:722-8.

8. Singh A, Singh S, Mathur V, Singh K. Transvaginal sonography in dysfunctional uterine bleeding and its correlation with histopathology. J Obstet Gyunecol of India. 2001;51(6): 116-9.

9. Veena A, Seema M, Anita R. Evaluation of dysfunctional uterine bleeding by TVS: Hysteroscopy and Histopathology. J Obstet Gynecol. 2003;53:170-7.

10. Al-Naaimy WMT, Ahmed M, Al-Jawadi SI. Histopathological interpretation of abnormal uterine bleeding after the age of 40 years. Iraqi Postgraduate Med J. 2010;9(3):274-82.

11. Bhosle A, Fonseca M. Evaluation and histopathological correlation of abnormal uterine bleeding in perimenopausal women. Bombay Hospital J. 2010;52(1):69-72.

12. Khan S, Nawaz S. A comparison of pelvic examination, pelvic ultrasound and preoperative findings in ovarian masses. APMC. 2008;2(2):121-5.

13. Subhankar D, Barunoday C, Rejaul K, Kanti AR, Kumar MP, Kumar GT. Abnormal uterine bleeding in perimenopausal age. Diagnostic options and accuracy. J Obstet Gynecol. 2011;61:189-94.

14. Cacciatore $B$, Leminen $A$, Ingman-Triberg $S$, Ylöstalo P, Paavonen J. Transvaginal sonographic findings in ambulatory patients with suspected pelvic inflammatory diseases. Obstet Gynecol. 1992;80:912-6.

15. Gaitan H, Angel E, Diaz R, Parada A, Sanchez L. Accuracy of five different diagnostic technique in mild to moderate pelvic inflammatory disease. Infect Dis Obstet Gynecol. 2002;10:171-80.

16. Tongsong T, Wanapirak C, Sukpan K, Khonamornpong S, Pathumbal A. Subjective sonographic assessment for differentiation between malignant and benign adnexal masses. Asian Pacific J Cancer Prev. 2006; 7:124-6.

17. Batra S, Gupta S, Gandhi G. Sensitivity of transvaginal sonography versus clinical and operative findings. J Obstet Gynecol. 1998.

Cite this article as: Mise PJ, Mise SJ, Mise A, Siddappa M. Role of transvaginal sonography in various gynecological disorders. Int J Reprod Contracept Obstet Gynecol 2017;6:3138-42. 